\title{
Correction to: Hyperglycaemia cause vascular inflammation through advanced glycation end products/early growth response-1 axis in gestational diabetes mellitus
}

\author{
Barathi Rajaraman ${ }^{1}$. Nirupama Ramadas ${ }^{1}$. Sundar Krishnasamy ${ }^{1}$. Vidya Ravi ${ }^{2}$ - Atima Pathak ${ }^{3}$. C. S. Devasena ${ }^{3}$. \\ Krishnan Swaminathan ${ }^{4}$. Arunkumar Ganeshprasad ${ }^{1}$. Ashok Ayyappa Kuppuswamy ${ }^{1} \cdot$ Srinivasan Vedantham $^{1}$
}

Published online: 15 December 2021

(c) Springer Science+Business Media, LLC, part of Springer Nature 2021

\section{Correction to: \\ Molecular and Cellular Biochemistry (2019) 456:179-190 https://doi.org/10.1007/s11010-019-03503-0}

In the original publication of the article, Table 1 was published incorrectly. The correct version of Table 1 is provided in this correction.

The original article can be found online at https://doi.org/10.1007/ s11010-019-03503-0.

Srinivasan Vedantham srinivasan.vedantham@gmail.com

1 School of Chemical and Biotechnology, SASTRA Deemed to be University, Thanjavur, Tamil Nadu, India

2 Dept. of Obstetrics \& Gynaecology, K.A.P. Vishwanatham Government Medical College, Trichy, Tamil Nadu, India

3 Dept. of Obstetrics \& Gynaecology, Kovai Medical Centre and Hospital, Coimbatore, Tamil Nadu, India

4 Dept. of Endocrinology, Kovai Medical Centre and Hospital, Coimbatore, India 
Table 1 Clinical characteristics and anthropometric measures of the study subjects

\begin{tabular}{l} 
Status of the women \\
\hline Age (years) \\
*Baby birth weight $(\mathrm{kg})$ \\
*BMI $\left(\mathrm{kg} / \mathrm{m}^{2}\right)$ \\
*Systolic BP $(\mathrm{mm} \mathrm{Hg})$ \\
*Diastolic BP $(\mathrm{mm} \mathrm{Hg})$ \\
FBS $(\mathrm{mg} / \mathrm{dl})$ \\
PPBS $(\mathrm{mg} / \mathrm{dl})$ \\
Data presented as mean \pm SEM \\
*Data available in subset \\
** $p<0.05$
\end{tabular}

Publisher's Note Springer Nature remains neutral with regard to jurisdictional claims in published maps and institutional affiliations. 